\title{
Topical and systemic analgesia versus caudal epidural and dorsal penile nerve block in relieving pain after pediatric circumcision
}

\author{
Ayse KARATAS (D, E. Zeynep ETI D, Tumay UMUROGLU D, Seniyye Ulgen ZENGIN (D), F. Yilmaz GOGUS (D) \\ Department of Anesthesia and Intensive Care, School of Medicine, Marmara University Teaching and Research Hospital, Istanbul, Turkey.
}

Corresponding Author: Seniyye Ulgen ZENGIN

E-mail: ulgen_t@yahoo.com

Submitted: 23.02.2021 Accepted: 06.05.2021

\begin{abstract}
Objective: There is no consensus on the use of optimal analgesic method after pediatric circumcision, although, caudal block (CB), dorsal penile nerve block (DPNB), topical local anesthetic application and systemic analgesic administration are frequently used methods. In this study, we aimed to compare the postoperative analgesic effects and side effects, as well as parental satisfaction concerning these methods.

Patients and Methods: Eighty children, aged 3-12 years, undergoing circumcision were randomized into four groups ( $\mathrm{n}=20$ ). Group Caudal Anesthesia (CA), Group Dorsal Penile Blok (DP), Group Topical Analgesia (TA), Group Systemic Analgesics (SA). The severity of pain was measured with NRS or CHEOPS scores. Time to awakening, first analgesic requirement, hospital discharge, side effects and parental satisfaction were recorded.

Results: In groups CA and DP, pain scores during the first postoperative hour were lower than the pain scores of other groups and in group CA, the first analgesic requirement time was significantly longer compared to other groups $(\mathrm{p}<0.05)$. In the early postoperative hour, parental satisfaction was higher in group CA compared to other groups.

Conclusion: In the early postoperative period, CB and DPNB reduce pain more effectively and provide more parental satisfaction than other applications, (in children who underwent) circumcision.

Keywords: Circumcision, Pain, Postoperative, Dorsal penile nerve block Caudal epidural block, EMLA
\end{abstract}

\section{INTRODUCTION}

Providing an effective postoperative analgesia is essential following pediatric day case surgery in children [1]. Circumcision is a minor and day case surgery, usually represented as the most undertaken procedure on a day case basis, and it usually ends up with significant postoperative pain and distress $[2,3]$. Pain leading to involuntary movements in the early postoperative period may result in bleeding at the operative site.

Ideal analgesia method after circumcision should provide an immediate, long lasting and effective pain relief with minimal to no side effects. Nonsteroidal anti-inflammatory agents (NSAIDs) and opioids are the most widely used systemic analgesics after circumcision, however, their use may be limited because of the inadequate analgesic effects of NSAIDs, when used alone and the potential adverse effects of opioids [1]. Although, local anesthetic techniques such as Caudal Block (CB) and Dorsal Penile Nerve Block (DPNB) have been shown to be more effective than the administration of systemic opioids after circumcision, CB may be complicated with motor block or delayed micturition [4]. Studies on the effectivity of DPNB have also conflicting results with a reported overall failure rate being $4-6 \%[3,5]$. The topical administration of local anesthetic (LA) agents seems to be promising for its noninvasiveness [6], although, some authors claim that topical analgesia is not effective [2]. All in all, the best and minimal invasive method in relieving post circumcision pain has not yet been determined and a Cochrane review on this subject claims that trials comparing all the methods are still lacking [4].

Our aim was to compare the early postoperative analgesic effects, side effects and parental satisfaction regarding four analgesic methods; CB, DPNB, topical and systemic analgesic administration in children undergoing elective circumcision.

How to cite this article: Karatas A, Eti EZ, Umuroglu T, Zengin US, Gogus FY. Topical and systemic analgesia versus caudal epidural and dorsal penile nerve block in relieving pain after pediatric circumcision. Marmara Med J 2021; 34(3):292-297. doi: 10.5472/marumj.1013317 


\section{PATIENTS and METHOD}

After obtaining ethical committee approval (Ethics Committee Approval: Decision No. 82 dated 24.09.2010 from the Turkish Ministry of Health, General Directorate of Pharmaceuticals and Pharmacy, Pharmaceutical Clinical Research Ethics Advisory Board-I) and written informed consent of the parents, eighty boys aged between 3-12 years, scheduled for circumcision were enrolled into the study. The study design was prospective, randomized, controlled and comparative. Randomization was done by a sealed envelope method. Exclusion criteria were parental refusal, history of coagulopathy, atopic dermatitis or allergy to local anesthetics, history of methemoglobinemia and contraindication to NSAIDs or CB, history of developmental delay or mental retardation which might disturb the pain intensity assessment, neurological diseases, and analgesic use in the previous week of the surgery.

Patients were allocated into four groups:

Group CA $(n=20)$ received caudal block with $0.25 \%$ bupivacaine in $1 \mathrm{ml} / \mathrm{kg}$, after anesthesia induction;

Group DP $(\mathrm{n}=20)$ received DPNB with $0.25 \%$ bupivacaine in $0.3 \mathrm{ml} / \mathrm{kg}$, after anesthesia induction;

Group TA $(n=20)$ received topical analgesia, one hour before anesthesia induction.

Group SA (Control group) $(n=20)$ received systemic analgesics (rectal paracetamol after anesthesia induction, rectal or oral paracetamol postoperatively). General anesthesia was induced with thiopental $5-7 \mathrm{mg} / \mathrm{kg}$ IV or inhalation of $8 \%$ sevoflurane with $70 \% \mathrm{~N}_{2} \mathrm{O}$ in oxygen in children who refuse intravenous line access. Muscle relaxation was maintained with $0.5 \mathrm{mg} / \mathrm{kg}$ atracurium bromide IV. An appropriate-sized laryngeal mask airway was inserted and anesthesia was maintained with 1 MAC sevoflurane and $70 \% \mathrm{~N}_{2} \mathrm{O}$ in oxygen.

Topical analgesia with $3 \mathrm{~g}$ 2.5\% lidocaine and $2.5 \%$ prilocaine cream, eutectic mixture of local anesthetics (EMLA) was applied to the distal half of the penis under an occlusive dressing, one hour before the surgery, in the preoperative room before the assistance of the parents (Group TA). Application did not include the mucosal surface. CB was performed by the same experienced anesthesiologist with $0.25 \%$ bupivacaine hydrochloride, $1 \mathrm{mLkg}^{-1}$ (maximum $20 \mathrm{~mL}$ ) (Group CA). DPNB was performed by the same experienced pediatric surgeon, with infiltration of $0.3 \mathrm{mLkg}^{-1} 0.25 \%$ bupivacaine hydrochloride to both sides of the pubic arch via a $21 \mathrm{G}$ needle (Group DP). In group SA, $40 \mathrm{mgkg}^{-1}$ paracetamol were given rectally after the induction of anesthesia, $20 \mathrm{mgkg}^{-1}$ paracetamol rectally or orally four times a day were administered postoperatively.

Heart rate, non-invasive blood pressure, peripheral oxygen saturation $\left(\mathrm{SpO}_{2}\right)$, end-tidal carbon dioxide pressure $\left(\mathrm{ETCO}_{2}\right)$ and sevoflurane concentrations were monitorized and recorded with 15 minute intervals peroperatively.

Postoperative pain intensity was assessed with a 10-point numeric rating scale (NRS) ( $0=$ none, $1-3=$ mild, $4-6=$ moderate, $7-10=$ severe) in children older than 6 years (school-aged) or with
Children's Hospital of Eastern Ontario Pain Scale (CHEOPS: minimum score 4 points and maximum score 13 points) in younger (preschool) children [7].

Pain scores were recorded at $0,2^{\text {nd }}$, and $4^{\text {th }} \mathrm{h}$ postoperatively. In the postanesthesia care unit or in the ward, $1 \mathrm{mgkg}^{-1}$ meperidine hydrochloride intravenously was administered whenever NRS scores were higher than 3 or CHEOPS scores were higher than 5. All data collection was done by an anesthesiologist who was blinded to the group assignment. At the end of anesthesia, awakening times (time to follow verbal commands after the discontinuation of sevoflurane), the first analgesic requirement time, the need for rescue analgesic, the first urination, mobilization and hospital discharge time, adverse effects and parental satisfaction via a 4 -point scale, edited by researchers ( $4=$ very satisfied, $3=$ satisfied, $2=$ dissatisfied, $1=$ very dissatisfied) were recorded.

\section{Statistical analysis}

Statistical evaluation of the collected data was performed using GraphPad Instat Version 3.00 for Windows 95. The primary outcome was pain scores as measured by NRS or CHEOPS. Secondary endpoints included the first analgesic requirement time, the need for rescue analgesic, the first urination, mobilization and hospital discharge time, adverse effects and parental satisfaction. Sample size was calculated based on previous studies [8] to detect a difference of 2 in CHEOPS pain scores at early postoperative hours, between groups with a standard deviation of 2.75. At the end, we found that at least 20 patients in each group required to demonstrate a significant difference for a type I error of 0.05 and a power of 0.8 . Repeated measures of ANOVA were used to analyze the variations of parameters in different times. Tukey's test was considered as posthoc analysis. Non parametric data were evaluated with KruskalWallis and Mann-Whitney U tests. Chi-square or Fisher's exact test were used to evaluate the proportional variables. Data were expressed as mean \pm standard deviation (SD). A p value less than 0.05 was considered as statistically significant.

\section{RESULTS}

Descriptive analysis of the patients' demographic and clinical characteristics is shown in Table I. Demographic datas, duration of surgery and anesthesia were similar.

While the heart rate did not differ between the groups in the first 15 minutes peroperatively ( $p>0.05$ ), the 30th minute value was significantly lower in Group CA compared to other groups ( $\mathrm{p}$ $<0.05)$. Table II shows peroperative heart rates and mean arterial pressures.

Table III shows awakening, first mobilization, first urination and hospital discharge times.

Figure 1 shows the pain scores evaluated with CHEOPS. At the first postoperative measurement time (0.s), CHEOPS values were significantly lower in Group CA and Group DP than in Group TA and Group SA $(\mathrm{p}<0.05)$. There was no significant difference between the groups at other measurement times $(\mathrm{p}>0.05)$. 
There was no significant difference between the groups in terms of weaning time, first analgesic requirement time, first mobilization time, first urination time $(p>0.05)$. The proportion of patients who required additional analgesics during the study was significantly lower than Group TA and Group SA in Group CA and DP $(\mathrm{p}<0.05)$.

Figure 2 shows the NRS scores evaluated with NRS. In Group CA, NRS scores were significanty lower than the scores in Group TA and Group SA.
Figure 3 shows additional analgesic requirement. In Group CA, analgesic requirement was significantly lower than the analgesic requirement for Group TA and Group SA.

Figure 4 shows the parental satisfaction scores. Parental satisfaction with analgesia for Group CA and Group DP was significantly higher than the parental satisfaction for Group TA and Group SA.

Table I. Descriptive analysis of the patients' demographic and clinical characteristics.

\begin{tabular}{|c|c|c|c|c|c|}
\hline & $\begin{array}{l}\text { Group CA } \\
\qquad(\mathrm{n}=20)\end{array}$ & $\begin{array}{l}\text { Group DP } \\
\qquad(\mathrm{n}=20)\end{array}$ & $\begin{array}{l}\text { Group TA } \\
\qquad(n=20)\end{array}$ & $\begin{array}{c}\text { Group SA } \\
\quad(n=20)\end{array}$ & p value \\
\hline & Mean $( \pm \mathrm{SD})$ & Mean $( \pm \mathrm{SD})$ & Mean $( \pm \mathrm{SD})$ & Mean $( \pm S D)$ & \\
\hline Age (years) & $6.70( \pm 2.60)$ & $5.93( \pm 2.98)$ & $5.68( \pm 3.20)$ & $5.55( \pm 2.88)$ & 0,59 \\
\hline Weight (kg) & $24.40( \pm 7.88)$ & $24.50( \pm 11.87)$ & $21.20( \pm 6.93)$ & $21.15( \pm 5.87)$ & 0,39 \\
\hline $\begin{array}{l}\text { Duration of anesthesia } \\
\text { (min) }\end{array}$ & $42.60( \pm 11.21)$ & $37.35( \pm 5.12)$ & $37.35( \pm 13.95)$ & $39.30( \pm 10.58)$ & 0,35 \\
\hline Duration of surgery & $28.40( \pm 9.77)$ & $29.70( \pm 5.47)$ & $27.50( \pm 11.77)$ & $30.40( \pm 8.59)$ & 0,75 \\
\hline
\end{tabular}

(min)

All data are presented as mean ( \pm Standard Deviation). ANOVA test

Table II. Peroperative heart rate and mean arterial pressure values

\begin{tabular}{|c|c|c|c|c|c|c|}
\hline & & HR (Beats/min) & & & $\mathrm{Hg})$ & \\
\hline & $0 \mathrm{~min}$ & 15. $\min$ & 30. $\min$ & $0 \mathrm{~min}$ & 15. $\min$ & 30. $\min$ \\
\hline Group CA & $123.4( \pm 19.2)^{*}$ & $112.1( \pm 19.7)$ & $100.6( \pm 18.4)^{\star} \perp$ & $80.5( \pm 11.4)^{*}$ & $67.7( \pm 9.5)^{\star}$ & $65.8( \pm 8.4)^{*}$ \\
\hline Group DP & $118.9( \pm 20.6)$ & $117.7( \pm 18.3)$ & $115.4( \pm 18.0) \perp$ & $81.1( \pm 14.1)$ & $71.8( \pm 13.7)$ & $71.7( \pm 12.0)$ \\
\hline Group TA & $123.8( \pm 19.0)$ & $122.9( \pm 18.6)$ & $115.6( \pm 14.5) \perp$ & $75.0( \pm 11.0)$ & $73.9( \pm 9.1)$ & $73.7( \pm 9.9)$ \\
\hline Group SA & $120.4( \pm 21.9)$ & $125.2( \pm 16.4)$ & $117.7( \pm 15.3) \perp$ & $73.3( \pm 13.5)$ & $75.2( \pm 11.7)$ & $71.9( \pm 8.9)$ \\
\hline
\end{tabular}

Table III. Awakening time, first analgesic requirement, first mobilization, first urination and hospital discharge times

\begin{tabular}{|c|c|c|c|c|}
\hline & $\begin{array}{c}\text { Group CA } \\
(\mathrm{n}=20)\end{array}$ & $\begin{array}{c}\text { Group DP } \\
(\mathrm{n}=20)\end{array}$ & $\begin{array}{c}\text { Group TA } \\
(\mathrm{n}=20)\end{array}$ & $\begin{array}{c}\text { Group SA } \\
\quad(n=20)\end{array}$ \\
\hline Awakening time (min) & $6.03 \pm 4.46$ & $7.65 \pm 4.22$ & $7.95 \pm 4.94$ & $7.03 \pm 3.69$ \\
\hline $\begin{array}{l}\text { First analgesic requirement } \\
\text { time (min) }\end{array}$ & $25.33 \pm 16.48^{*}$ & $6.30 \pm 4.27^{*}$ & $5.16 \pm 5.04^{*}$ & $3.95 \pm 3.35^{*}$ \\
\hline First mobilization time (hr) & $2.45 \pm 1.28$ & $1.75 \pm 1.16$ & $1.45 \pm 0.71$ & $1.98 \pm 1.49$ \\
\hline First urination time (hr) & $2.68 \pm 1.23^{* *}$ & $1.98 \pm 1.21$ & $1.30 \pm 0.75^{* *}$ & $2.23 \pm 1.61$ \\
\hline Discharge time (hr) & $4.35 \pm 0.99$ & $3.93 \pm 1.08$ & $3.70 \pm 1.19 \dagger$ & $4.73 \pm 1.21 \dagger$ \\
\hline
\end{tabular}

Data are expressed as mean $\pm S D$, ${ }^{*} p<0.0001$, Group CA compared to other groups, ${ }^{* *} p<0.01$, Group CA, compared to group TA, $\dagger p<0.05$, Group TA compared to group SA, ANOVA test (with posthoc Tukey test) 


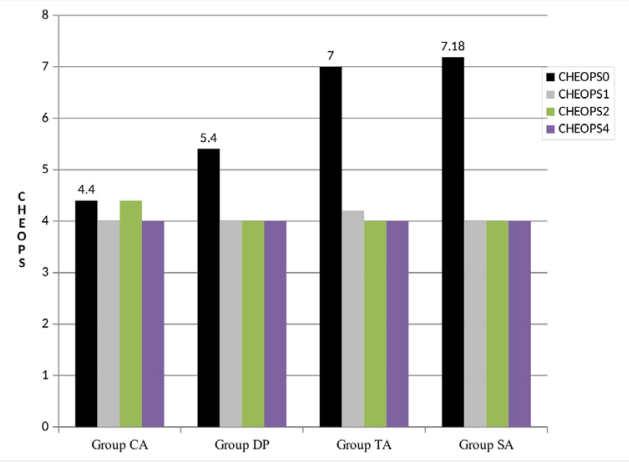

Figure I. Postoperative CHEOPS pain scores ${ }^{*}, p<0.05$ Group CA compared to groups TA and $S A$ **, $p<0.05$ Group DP compared to groups TA and $S A$ Kruskal Wallis/Mann-Whitney U tests

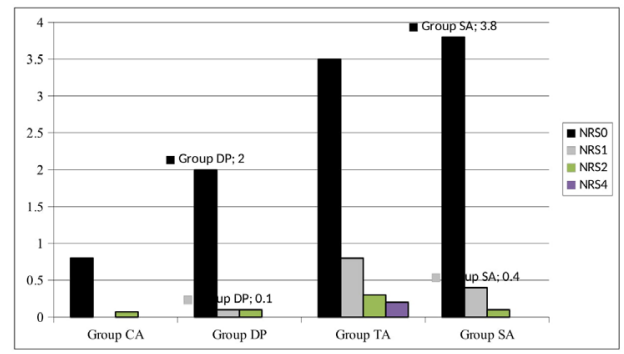

Figure 2. Postoperative NRS scores

$*, p<0.05$ Group CA compared to groups TA and SA

${ }^{*}, p<0.05$ Group CA compared to group TA

Kruskal Wallis/Mann-Whitney U tests

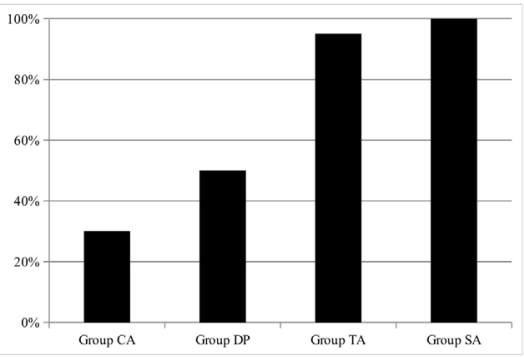

Figure 3. Percent of patients requiring additional analgesic(\%)

*, $p<0.05$ Group CA compared to groups TA and $S A$ $\dagger, p<0.05$ Group DP compared to groups TA and SA Chi-square test

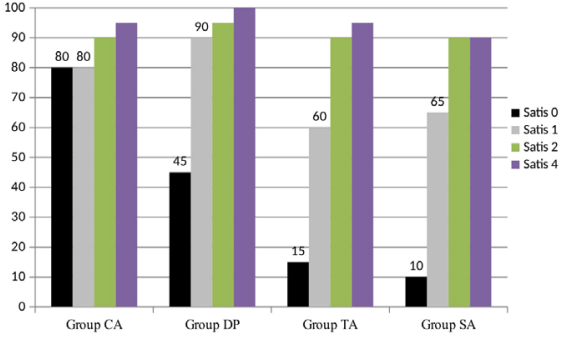

Figure 4. Prental satisfaction (score of 4)

*, $p<0.05$ Group CA compared to groups DP, TA and SA

$* *, p<0.05$ Group DP compared to groups TA and $S A$

$\dagger, p<0.05$ Group CA compared to groups TA and $S A$

$\uparrow, p<0.05$ Group DP compared to groups TA and SA

Kruskal Wallis/Mann-Whitney U tests

\section{DISCUSSION}

The main result of this study is that the first term postoperative analgesic effects of $\mathrm{CB}$ and $\mathrm{DPNB}$ are more prominent compared to noninvasive methods, in children undergoing circumcision. In regard of the parental satisfaction, they also offered advantageous findings. In other words, noninvasive methods such as topical LA application and less invasive method such as systemic analgesic administration appeared to be less effective than invasive methods in reducing pain during the early postoperative period.

Circumcision is a minor but painful surgery and children deserve to receive adequate analgesia during the immediate post-circumcision period. Early postoperative pain results in crying and agitation with excessive body movements leading to an increased risk for bleeding at the surgical site. So, the ideal analgesia method after circumcision would provide effective pain relief with minimal side effects.

Systemic analgesics such as opioids (pethidine hydrochloride, morphine sulphate and codeine) or NSAIDs are routinely administered in relieving postoperative pain following circumcision in children. Even though, these drugs are effective as painkillers, their unwanted side effects limit their use: opioids are usually administered in subtherapeutic doses as a result of the fear of opioid induced sedation, respiratory depression, nausea or urinary retention. NSAIDs are generally used as adjuvants to opioids in order to reduce their doses, as well as the incidence of side effects [9]. Nevertheless, nephrotoxicity, gastrointestinal bleeding and thrombocyte dysfunction stand as limiting factors in the use of NSAIDs [9]. To overcome these disadvantages, the application of local anesthetic techniques such as CB and DPNB in relieving post circumcision pain, became popular $[10,11]$. The main limiting factor of these methods is their invasiveness. Topical analgesia for pain relief seems promising but repeated application is usually required. Up to date, most of the studies concerning the effectivity of the methods compared only two 
methods, so we aimed to compare the most commonly used four methods and find the optimal one to provide post circumcision analgesia.

Caudal Block is the most commonly performed pediatric regional analgesia technique in children undergoing perineal surgery. Major disadvantages of $\mathrm{CB}$ are urinary retention and lower extremity motor block, leading to the denial of its routine use as an ideal method in day case surgeries [10]. Local anesthetic agent concentration is the major determinant of the degree of motor block. Wolf et al., determined that in caudal anesthesia, the use of bupivacaine at a concentration of $0.125 \%$ instead of $0.25 \%$ resulted in a lower incidence of motor block, whereas a further reduction in bupivacaine concentration to as low as $0.0625 \%$ resulted in a lower incidence of motor block with less analgesic effect [13]. We used $0.25 \%$ bupivacaine and motor block was only observed in two children. This finding does not overlap with the suggestion of the Cochrane review which claims that due to the possible risk of motor weakness, CB should not be performed in children old enough to walk, in day case surgeries [4]. The low incidence of motor block in our study was probably related to the low concentration of LA, and we believe that $\mathrm{CB}$ is an advantageous method to reduce pain after circumcision, as long as temporary leg weakness is prevented with reduced LA concentration. It is true that the ideal agent, dose, and concentration for a caudal block has not yet been determined as previously reported [2].

Dorsal Penile Nerve Block has the advantages of providing rapid recovery, early urination and discharge times, after circumcision [11-13]. In this method, there is no need to change the patient's position from supine to the lateral decubitus and a substantial number of studies claim that it provides analgesia as effective as CB $[10,13]$. In our study, DPNB resulted in lower CHEOPS scores in the immediate postoperative period and in higher parental satisfaction than noninvasive (topical LA administration) and control (systemic analgesic administration) groups. Although, time to first analgesic requirement was significantly shorter than $\mathrm{CB}, \mathrm{DPNB}$ offered advantageous findings regarding lower number of children requiring additional analgesics than topical and systemic analgesia groups.

The incidence of side effects in DPNB is less compared to CB and only described as bleeding or hematoma formation at the site of injection [15]. The occurrence of penile ischemia is out of question if large volumes of LA agents and epinephrine containing solutions are avoided [16]. We did not observe any side effect with DPNB. Naja $Z$ et al., suggested that DPNB is a blind approach since, its application relies on the subjective estimation of the dorsal nerve location in the Buck's fascia [3].

In terms of $\mathrm{CB}$, volumes and concentrations used in our study were similar to those used in the literature $(0.25 \%$ bupivacaine, $1 \mathrm{mlkg}^{-1}$ ); but the concentration of bupivacaine used in DPNB was lower than that used in Weksler's study $(0.25 \%$ versus $0.5 \%)$, volumes being similar [11-13]. In the aforementioned study, although the induction, skin incision and hospital discharge times were shorter than the $\mathrm{CB}$ group, the administration of high concentration of bupivacaine in DPNB made no difference in terms of postoperative analgesia. In Beyaz et al., study CB was performed with $0.25 \%$ levobupivacaine $\left(0.5 \mathrm{mlkg}^{-1}\right)$ and DPNB with $0.25 \%$ levobupivacaine $\left(0.5 \mathrm{mlkg}^{-1}\right)$ and analgesic efficacies, additional analgesic requirements were similar [15]. Margetts et al., as well, used $0.5 \%$ bupivacaine $\left(0.25 \mathrm{mlkg}^{-1}\right)$ in DPNB and found no difference in analgesic efficacy when compared to $\mathrm{CB}$ performed with $0.25 \%$ bupivacaine $\left(0.5 \mathrm{mlkg}^{-1}\right)$ with the addition of ketamine [18]. Regarding the concentrations and volumes used in our study, we also found equipotent analgesic efficacy between CB and DPNB in the immediate and early postoperative hours, with no difference in hospital discharge times. We question the necessity of using high concentrations and high volumes in DPNB. As mentioned earlier, we believe that administering low LA concentrations in CB may prevent motor block and make its use convenient in day case surgeries.

Topical LA application has a single side effect that manifests as a skin reaction, but it is suggested that it does not provide analgesia as effective as DPNB [19]. The reason of this suggestion may lie in the application time of the LA (EMLA) cream. Sufficient time must be allowed for it to become effective. There will not be enough time left to begin its effect if it is applied at the end of the surgery. Choi et al., performed topical analgesia one hour before surgery and determined that analgesia is as effective as DPNB but with a shorter duration of action [19]. We also applied EMLA cream one hour before surgery. Pain scores at the immediate postoperative hour and patient number requiring additional analgesics were higher in group TA than groups CA and DP. The ineffective analgesic profile of the topical LA application may be explained by the removal of LA from the surgical site during the sterilization period and loss of the effectivity of the cream. This explanation is also supported by some authors [19]. This problem may be solved by lengthening the application time to at least two h before surgery. Additionally, we performed DPNB with bupivacaine, a long lasting and more potent LA compared to lidocaine and prilocaine found in EMLA and this explains that the analgesic efficacy of DPNB was not observed in TA group. In this point, topical analgesia only seems to be advantageous due to its noninvasiveness and we recommend that it should not be used as the sole method of analgesia. This recommendation is also supported by Paix et al [3].

In summary, in the immediate postoperative period, $\mathrm{CB}$ and DPNB reduce pain more effectively and provide more parental satisfaction than topical and systemic analgesic applications, in children undergoing circumcision. Need for an additional analgesic requires longer time in $\mathrm{CB}$ and DPNB. There is a misconception that these blocks are difficult to perform and time-consuming, but our present study demonstrated that they are more effective in post circumcision pain relief compared to noninvasive and systemic methods. TA may only decrease the need for supplementary analgesics.

\section{Compliance with Ethical Standards}

Ethical approval: Ethics Committee Approval: Decision No. 82 dated 24.09.2010 from the Turkish Ministry of Health, General Directorate of Pharmaceuticals and Pharmacy (Pharmaceutical Clinical Research Ethics Advisory Board-I) 
Funding: This publication was prepared without any external source of funding.

Conflict of interest: All authors declare that there is no conflict of interest.

Authors' contributions: A.K.,E.Z.E.,F.Y.G. Idea/concept. A.K.,E.Z.E.,T.U. Design. E.Z.E.,T.U.,F.Y.G. Control/Supervision. A.K.,E.Z.E.,T.U. Data collection and processing.

A.K.,E.Z.E.,S.U.Z. Analysis. A.K.,E.Z.E.,S.U.Z.,F.Y.G. Literature review. A.K.,E.Z.E.,T.U. A.K./E.Z.E.,T.U.,S.U.Z.,F.Y.G. Critical review. A.K.,E.Z.E.,T.U.,S.U.Z References. All authors read and approved the final version of the article.

\section{REFERENCES}

[1] Lonnqvist PA, Morton NS. Paediatric day-case anaesthesia and pain control. Curr Opin Anaesthesiol 2006; 19:617-21. doi: 10.1097/ACO.0b013e3280101dab.

[2] Howard R, Carter B, Curry J, et al. Postoperative pain. Paediatr Anaesth 2008; 18:36-63. doi: 10.1111/j.14609592.2008.02431.x.

[3] Paix BR, Peterson SE. Circumcision of neonates and children without appropriate anaesthesia is unacceptable practice. Anaesth Intensive Care 2012; 40:511-6. doi: 10.1177/0310057X120.400.0318.

[4] Cyna AM, Middleton P. Caudal epidural block versus other methods of postoperative pain relief for circumcision in boys. Cochrane Database of Syst Rev 2008;4: Art No:CD003005. doi: 10.1002/14651858.CD003005.pub2

[5] Naja Z, Al-Tannir MA, Faysal W, Daoud N, Ziade F, El-Rajab M. A comparison of pudendal block vs dorsal penile nerve block for circumcision in children: a randomised controlled trial. Anaesthesia 2011; 66:802-7. doi: 10.1111/j.13652044.2011.06753.x

[6] Taddio A, Ohlsson A, Einarson TR, Stevens B, Koren G. A systematic review of lidocaine-prilocaine cream (EMLA) in the treatment of acute pain in neonates. Pediatrics 1998; 101:1-9. doi: 10.1542/peds.101.2.e1

[7] Linder SL, Winner P. Pediatric headache. Med Clin North Am. 2001;85:1037-53. doi:10.1016/s0025-7125(05)70358-8

[8] McGowan PR, May H, Molnar Z, Cunliffe M. A comparison of three methods of analgesia in children having day case circumcision. Paediatr Anaesth 1998; 8: 403-7. doi: 10.1046/j.1460-9592.1998.00270.x

[9] Lönnqvist PA, Morton NS. Postoperative analgesia in infants and children. Br J Anaesth 2005; 95:59-68. doi: 10.1093/bja/ aei065

[10] Jöhr M, Berger TM. Caudal blocks. Paediatr Anaesth 2012; 22:44-50. doi: 10.1111/j.1460-9592.2011.03669.x.

[11] Weksler N, Atias I, Klein M, Rosenztsveig V, Ovadia L, Gurman GM. Is penile block better than caudal epidural block for postcircumcision analgesia? J Anesth 2005; 19:36-9. doi: 10.1007/s00540.004.0287-8

[12] Munevveroglu C, Gunduz M. Postoperative pain management for circumcision; Comparison of frequently used methods. Pak J Med Sci 2020;36:91-95. doi:10.12669/pjms.36.2.505

[13] Wolf AR, Valley RD, Fear DW, Roy WL, Lerman J. Bupivacaine for caudal analgesia in infants and children: the optimal effective concentration. Anesthesiology 1988; 69: 102-6. doi: 10.1097/00000.542.198807000-00017.

[14] Tree-Trakarn T, Pirayavaraporn S. Post-operative pain relief for circumcision in children: comparison among morphine, nerve block and topical analgesia. Anesthesiology 1985; 62:519-22. doi: 10.1097/00000.542.198504000-00027.

[15] Beyaz SG. Comparison of postoperative analgesic efficacy of caudal block versus dorsal penile nerve block with levobupivacaine for circumcision in children. Korean J Pain 2011; 24:31-5. doi: 10.3344/kjp.2011.24.1.31.

[16] Sara CA, Lowry CJ. A complication of circumcision and dorsal nerve block of the penis. Anaesth Intensive Care. 1985; 13:7985. doi: 10.1177/0310057X850.130.0111.

[17] Burke D, Joypaul V, Thomson MF. Circumcision supplemented by dorsal penile nerve block with $0.75 \%$ ropivacaine: a complication. Reg Anesth Pain Med 2000; 25:424-27. doi: 10.1053/rapm.2000.7594.

[18] Margetts L, Carr A, McFadyen G, Lambert A. A comparison of caudal bupivacaine and ketamine with penile block for paediatric circumcision. Eur J Anaesthesiol 2008; 25: 1009-13. doi: $10.1017 /$ S026.502.1508004833.

[19] Choi WY, Irwin MG, Hui TWC, Lim HH, Chan KL. EMLA cream versus dorsal penile nerve block for postcircumcision analgesia in children. Anesth Analg 2003; 96: 396-99. doi: 10.1097/00000.539.200302000-00018. 